\title{
Ablation and Microstructure Imaging of Dentin-Enamel Junction Using Focused Electron Beam in an Environmental Scanning Electron Microscope
}

\author{
Donggao Zhao ${ }^{1}$, Rasoul Seyedmahmoud ${ }^{1}$, Jacob D. McGuire ${ }^{1}$, Yong Wang ${ }^{1}$, Mary P. Walker ${ }^{1}$, and \\ Jeffrey P. Gorski ${ }^{1}$ \\ ${ }^{1}$ School of Dentistry, University of Missouri-Kansas City, Kansas City, MO 64108
}

Focused electron beam or electron probe in an environmental scanning electron microscope (ESEM) is used to ablate and image a thin layer of mixed organic and inorganic interface between the human tooth's dentin and enamel phases. This thin layer is called the dentin-enamel junction (DEJ). Characterization of the DEJ properties, such as chemistry, width, morphology and microstructures, are critical for understanding tooth's biomechanical behavior, radiotherapy effect on the tooth, and other interfaces joining dissimilar materials $[1,2]$.

Chemically, the main component of human teeth is mineral hydroxylapatite $\mathrm{Ca}_{10}\left(\mathrm{PO}_{4}\right)_{6}(\mathrm{OH})_{2}$, which contains $39.89 \mathrm{wt} \% \mathrm{Ca}$. Enamel, the hard outer covering of the tooth, consists of more than $96 \mathrm{wt} \%$ inorganic hydroxylapatite, and the underlying dentin contains approximately $70 \mathrm{wt} \%$ hydroxylapatite. Compared to brittle enamel, the supporting dentin is more resilient, highly collagenous mineralized, and makes up the majority of the bulk tooth structure. Dentin has more biological components such as collagens and can absorb and distribute stresses from the enamel. The DEJ is a complex and critical structure bridging the enamel and dentin and preventing the propagation of cracks from enamel into dentin [3]. Previous studies indicate that there is a continuous gradient of organic components [1] and a transition zone of Ca distribution across the DEJ [4]. McGuire et al. [5] showed that type IV collagen exists at the DEJ. The estimated width of the DEJ from Raman microspectroscopy, energy dispersive spectrometry (EDS) and crack trajectory deviation varies significantly from a few $\mu \mathrm{m}$ [1, 6, and 4] to up to $150 \mu \mathrm{m}$ [7]. Such large variations are likely related to the so-called functional width of the DEJ, i.e., the width of the DEJ differs depending on the property that is studied [2].

Morphologically the DEJ has a three-tiered structure, large scallops from 25 to $100 \mu \mathrm{m}$; microscallops from 2 to $5 \mu \mathrm{m}$; and a small scale microstructure [1]. However, morphology and small scale internal microstructures of the DEJ remain largely unrevealed. In order to expose the small scale internal microstructure of the DEJ and image the extracellular matrix under the scalloped surface of the DEJ, we employed FEI/Philips XL30 FEG-ESEM and strong electron beam energy to ablate the DEJ. The experimental conditions were accelerating energy $25 \mathrm{kV}$, spot size 4, ESEM mode, $\mathrm{H}_{2} \mathrm{O}$ vapor pressure 1.5 Torr, and WD $\sim 15 \mathrm{~mm}$. The sample holder was cooled at $1^{\circ} \mathrm{C}$ with a Peltier thermoelectric stage connected to a mini-chiller at $15^{\circ} \mathrm{C}$. Since the specimen is relatively large, its temperature may not be exactly $1^{\circ} \mathrm{C}$. At chamber pressure 1.5 Torr and temperature $1{ }^{\circ} \mathrm{C}$, the relative humidity was approximately $30 \%$. The specimens imaged were third molar halves of human teeth which had undergone previous decalcification and/or protein extraction exposing the dentin-enamel junction. After the first few images, the specimens were ablated or bombarded at the same location by the electron beam for approximately 10 min at a higher magnification. Then a series of images were taken at different magnifications. Figure 1 shows that the interior surface within a scallop can be removed by the focused electron beam. The four images shown were taken with a time interval of approximately $10 \mathrm{~min}$. At a magnification of $8000 \mathrm{X}$, the internal structure beneath the scalloped surface of the DEJ was then revealed (Figure 2). 


\section{References}

[1] S.J. Marshall et al., J. European Ceramics Society 23 (2003), p. 2897-2904.

[2] M.P. Walker and B. A. Fricke, Dentin-Enamel Junction of Human Teeth. In "Wiley Encyclopedia of Biomedical Engineering”, ed. M. Akay, John Wiley \& Sons, Hoboken (2006), p 1061-1064.

[3] A. Nanci, Ten Cate's Oral histology: development, structure, and function. 7th ed. (2008), Mosby Elsevier, St. Louis.

[4] V.M. Dusevich et al., Microsc. Microanal. 18 (Suppl 2) (2012), p. 274-275.

[5] J.D. McGuire et al., J Dent Res. 93(10) (2014), p. 1028-34.

[6] C. Xu et al., Calcif. Tissue Int. 84(3) (2009), p. 221-228.

[7] X.D. Dong and N.D. Ruse, J. Biomed. Mater. Res. 66A (2003), p. 103-109.

[8] The authors acknowledge funding from NIH/NIDCR Grant R01DE021462.
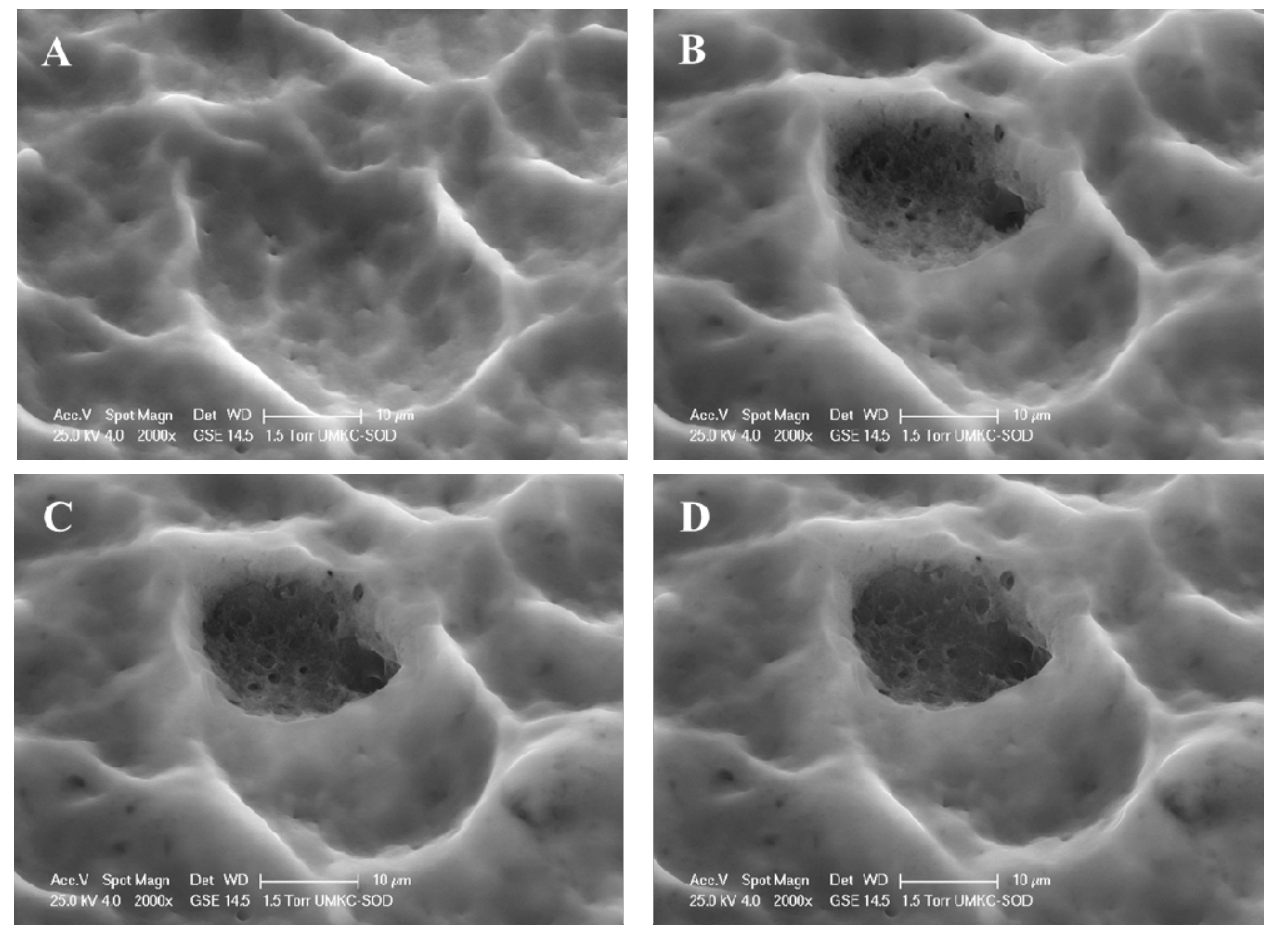

Figure 1. The interior surface of a scallop was removed and the internal structure beneath was revealed. Images A-D were taken at intervals of approximately 10 min between images.
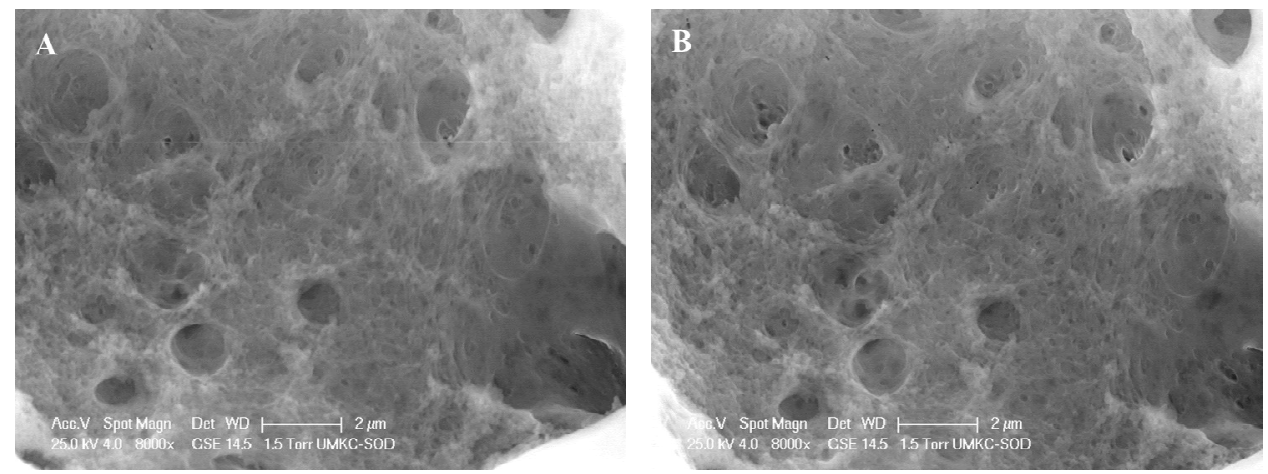

Figure 2. The underlying internal structure below the scalloped surface of the DEJ. Image A and B are zoomed in images corresponding to Image $\mathrm{C}$ and $\mathrm{D}$ in Figure 1, respectively. Differences in void are observed in the area off the center to the southwest direction. 